\title{
Using Thermoelectric Converters for Loop Heat Pipe Operating Temperature Control
}

\author{
Jentung $\mathrm{Ku}$ \\ NASA Goddard Space Flight Center \\ Greenbelt, Maryland, USA \\ Tel: 301-286-3130 \\ Jentung.Ku-1@nasa.gov \\ Hosei Nagano \\ NASA Visiting Researcher \\ Keio University \\ Tokyo, Japan
}

\begin{abstract}
This paper describes an experimental study to investigate the effectiveness of using thermoelectric converters (TECs) to control the loop heat pipe (LHP) operating temperature. Tests were conducted on an LHP having two evaporators and two condensers. Each evaporator has its own integral compensation chamber (CC). One side of the TEC is attached to the CC, and the other side is connected to the evaporator through a copper thermal strap. A bi-polar power supply is used to provide the power for the operation of each TEC. The bipolar supply will automatic change the direction of the current to the TEC depending on whether the CC requires heating or cooling in order to maintain its temperature at the desired set point. When cooling the $\mathrm{CC}$, the heat pumped by the TEC plus the power needed to operate the TEC is dissipated to the evaporator, and is ultimately transmitted to the condenser. When heating the CC, the TEC can draw heat from the evaporator to supplement the required control heater power. Test results showed that the TEC could control the LHP operating temperature within $\pm 1 \mathrm{~K}$ of the set point temperature. The control heater power required for TEC operation was also much less than that of using electrical heaters.
\end{abstract}

\section{Introduction}

A loop heat pipe (LHP) is a very robust and versatile heat transfer device which can transport large heat loads over long distance with small temperature differences [1-2] . Several LHPs are being used on several commercial communications satellites and NASA's ICESAT, SWIFT, and AURA spacecraft [3-6]. The LHP operating temperature is governed by the compensation chamber (CC) saturation temperature, which is a function of the evaporator heat load, the condenser sink temperature and the ambient temperature. If the $\mathrm{CC}$ is well insulated, the CC temperature is determined by the energy balance between the heat leak from the evaporator to the $\mathrm{CC}$ and the amount of subccoling carried by the returning liquid. For a given condenser sink temperature, both the heat leak and liquid subcooling are functions of the evaporator heat load. When the ambient temperature is higher than the condenser sink temperature, the CC temperature as a function of the evaporator power yields a well-known "V-shaped" curve as shown in Figure 1.

The LHP operating temperature can be controlled at a fixed set point required by the instrument. Temperature control is accomplished traditionally by cold-biasing the $\mathrm{CC}$ and using an electrical 
heater to maintain the set point temperature, as illustrated in Figure 2. The required control heater power can be as high as 30 percent of the evaporator heat load when the condenser sink is very cold. Another issue is that at low heat loads, the $\mathrm{CC}$ natural operating temperature may be higher than the desired set point. The traditional method of using electrical heaters cannot provide active cooling to the $\mathrm{CC}$ and the desired set point temperature cannot be maintained at very low heat loads.

A thermoelectric converter (TEC) can be used to provide both heating and cooling to the $\mathrm{CC}$, therefore extending the desired LHP operating temperature over a larger range of the evaporator heat load. One side of the TEC can be attached to the $\mathrm{CC}$, and the other side can be connected to the evaporator via a thermal strap. When the TEC is cooling the CC, the power applied to the TEC plus the heat that is absorbed from the $\mathrm{CC}$ is delivered to the hot side of the TEC. The heat is then transferred via the thermal strap to the evaporator, and is ultimately dissipated to the condensers. When the TEC is heating the $\mathrm{CC}$, part of the heat applied to the evaporator will be transmitted to the cold side of the TEC via the thermal strap. This heat plus the heat applied to the TEC is used to heat to CC. The TEC can therefore reduce the control heater power requirement for the $\mathrm{CC}$ when compared to the conventional method of using electrical heaters.

This paper presents the operation of a miniature loop heat pipe in a laboratory environment using TECs for temperature control. The test article and test setup will be presented first. This will be followed by descriptions of the tests conducted, and the experimental results that demonstrate the TEC's ability to control the loop operating temperature. Savings of the control heater power afforded by the TECs when compared to electrical heaters will also be discussed.

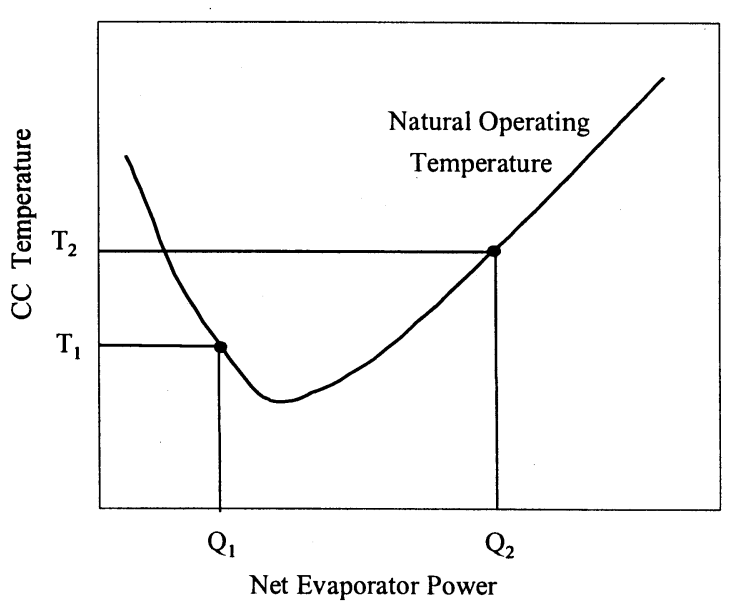

Figure 1 LHP Natural Operating Temperature

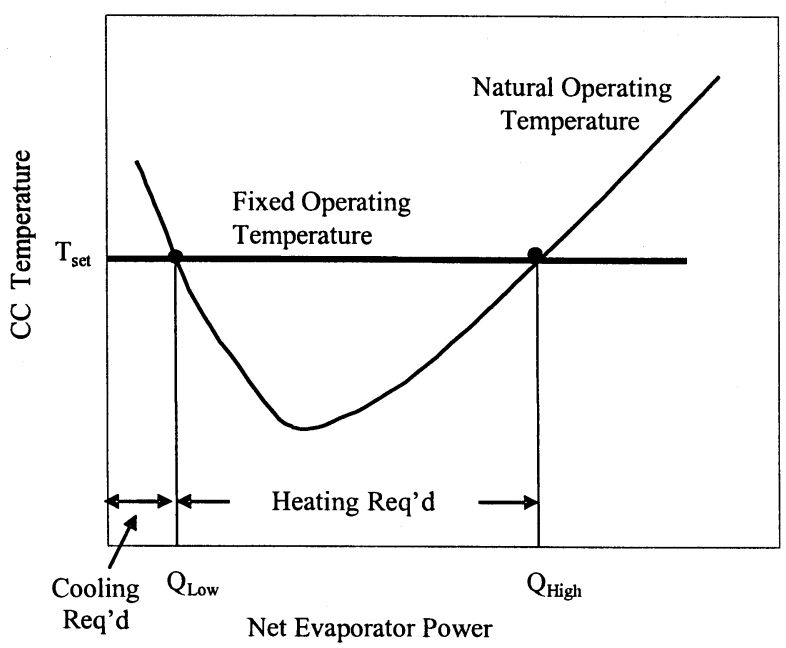

Figure 2 LHP Operating Temperature Control

\section{Test Article and Test Set-up}

The test article for this experimental study is a miniature LHP (MLHP) as shown in Figure 3. Major design parameters of the MLHP are summarized in Table 1. The MLHP consists of two parallel evaporators, two parallel condensers, a common vapor transport line and a common 
liquid return line. Each evaporator has a titanium wick that has an outer diameter (O.D.) of $63.5 \mathrm{~mm}$, an each evaporator has its own integral CC. The two parallel condensers are sandwiched between two aluminum plates. A flow regulator consisting of capillary wicks is installed at the downstream of the two condensers. In addition, the vapor line and liquid line are connected with several aluminum coupling blocks $(20 \mathrm{~mm}$ by $20 \mathrm{~mm}$ by $6 \mathrm{~mm}$ each). A TEC is installed on each CC through an aluminum saddle. The other side of the TEC is connected to the evaporator through a copper strap. A close view of the evaporator/CC section showing the TECs and thermal straps is shown in Figure 4.

Table 1. Summary of MLHP Design Parameters

\begin{tabular}{|c|c|c|}
\hline Component & Material & Value \\
\hline Evaporators (2) & Aluminum 6061 & $9 \mathrm{~mm}$ O.D. $\times 52 \mathrm{~mm} \mathrm{~L}$ \\
\hline Primary Wicks (2) & Titanium & $\begin{array}{l}\text { 6.35 mm O.D. x } 3.2 \mathrm{~mm} \mathrm{I.D} \\
\text { Porosity: } 0.35 \\
\text { Pore radius } 1.39 \mu \mathrm{m}(\mathrm{E} 1), 1.47 \mu \mathrm{m}(\mathrm{E} 2) \\
\text { Permeability: } 0.11 \times 10^{-13} \mathrm{~m}^{2}(\mathrm{E} 1) \\
\qquad 0.09 \times 10^{-13} \mathrm{~m}^{2}(\mathrm{E} 2)\end{array}$ \\
\hline $\begin{array}{l}\text { Secondary Wicks } \\
\text { (2) }\end{array}$ & Stainless Steel & $\begin{array}{l}\text { Porosity: } 0.67 \\
\text { Pore radius: } 68.7 \mu \mathrm{m} \\
\text { Permeability: } 83 \times 10^{-13} \mathrm{~m}^{2}\end{array}$ \\
\hline Bayonet Tubes (2) & SS 304L & $1.1 \mathrm{~mm}$ O.D. $\mathrm{x} 0.79 \mathrm{~mm}$ I.D. \\
\hline CC (2) & SS 304L & $22.2 \mathrm{~mm}$ O.D. $\times 21.2 \mathrm{~mm}$ I.D. $\times 72.4 \mathrm{~mm} \mathrm{~L}$ \\
\hline Vapor Line & SS 304L & $2.38 \mathrm{~mm}$ O.D. $x 1.37 \mathrm{~mm}$ I.D. $\times 914 \mathrm{~mm} \mathrm{~L}$ \\
\hline Liquid Line & SS 304L & $1.59 \mathrm{~mm}$ O.D. $x 1.08 \mathrm{~mm}$ I.D. $\times 914 \mathrm{~mm} \mathrm{~L}$ \\
\hline Condensers (2) & SS 304L & $2.38 \mathrm{~mm}$ O.D. $\mathrm{x} 1.37 \mathrm{~mm}$ I.D. $\mathrm{x} 2540 \mathrm{~mm} \mathrm{~L}$ \\
\hline Flow Regulator & & $\begin{array}{l}\text { Pore radius: } 10.1 \mu \mathrm{m} \\
\text { Permeability: } 3.1 \times 10^{-13} \mathrm{~m}^{2}\end{array}$ \\
\hline Working fluid & Ammonia & 29.3 gram \\
\hline Total LHP mass & & 316.6 gram \\
\hline
\end{tabular}

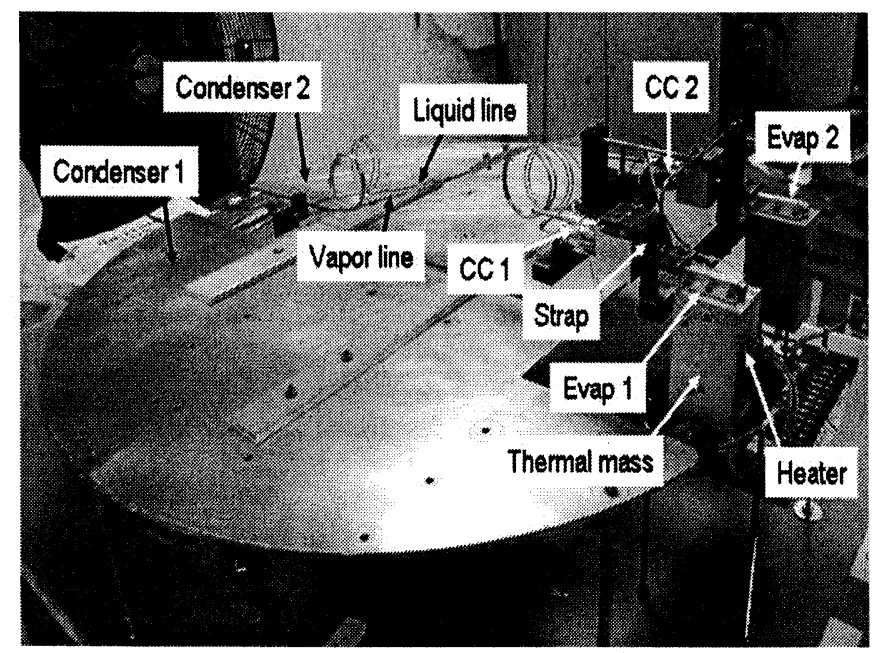

Figure 3 Picture of the MLHP 
A thermal mass of 400 grams of aluminum is attached to each evaporator to simulate the instrument mass. A cartridge heater capable of delivering $1 \mathrm{~W}$ to $200 \mathrm{~W}$ is inserted into each thermal mass. Each condenser is attached to a cold plate, and each cold plate is cooled convectively by a separate chiller. The two chillers allow temperatures of the two condenser plates to vary independently. Each TEC is controlled by a bi-polar power supply. The entire test set-up was placed in a horizontal plane.

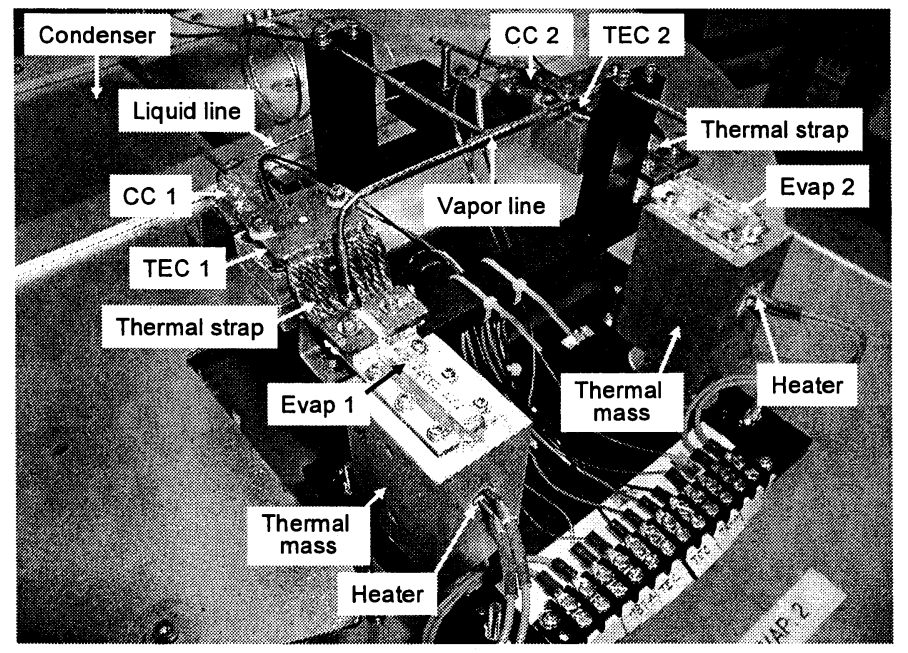

Figure 4 Close View of the MLHP Evaporator/CC Section

More than 60 type T thermocouples were used to monitor the MLHP temperature, as shown in Figure 5. Figure 6 shows the schematic of the TEC and thermal strap connections. A data acquisition system consisting of a data logger, a personal computer, and a screen monitor was used to collect and store temperature and power data every second. Labview software was used for the command and control of the test conditions.

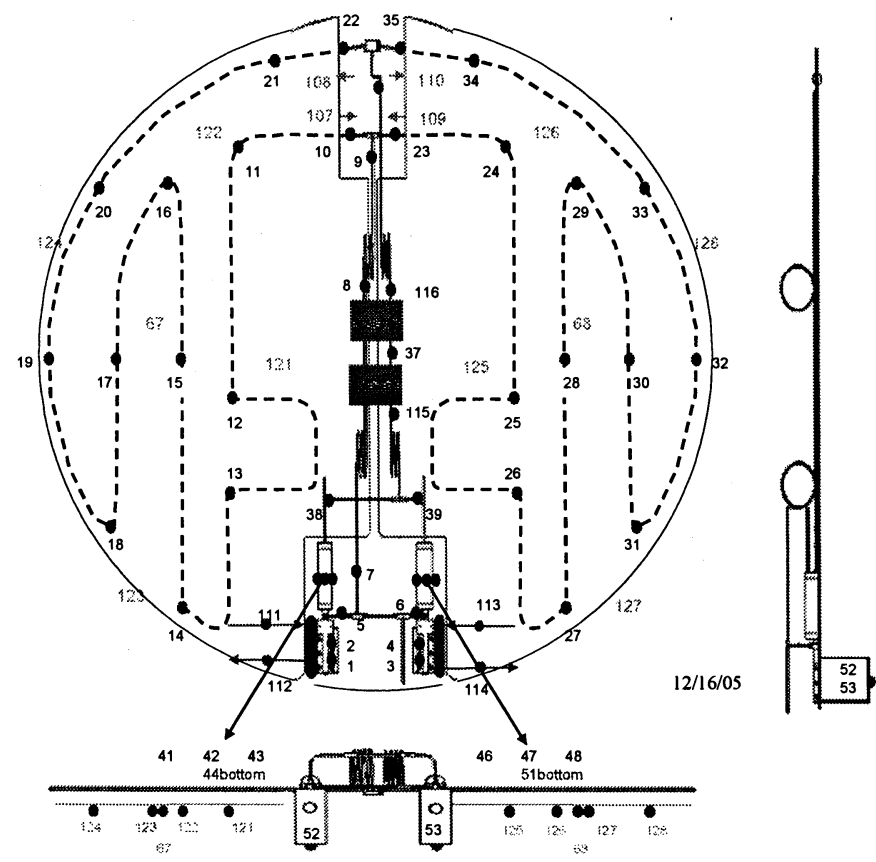


Figure 5 Thermocouple Locations in MLHP

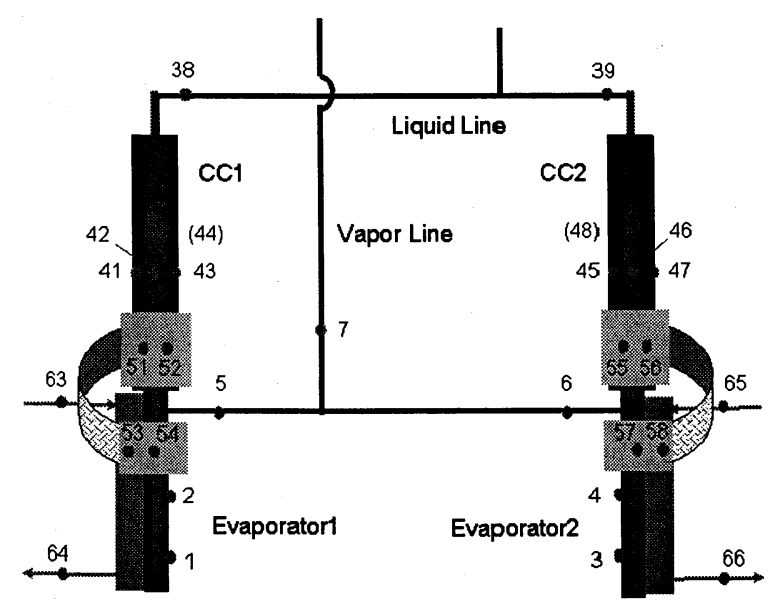

Figure 6 Thermocouples near Evaporators and CCs

\section{Tests Performed and Experimental Results}

Extensive tests were conducted to demonstrate the effectiveness of using TECs to control the LHP operating temperature. These tests encompassed a wide range of heat loads and condenser sink temperatures. Tests performed included power cycle with even and uneven powers to the two evaporators, sink temperature cycle, high power, low power, and $\mathrm{CC}$ set point temperature change. Most tests were conducted with and without using the TECs. For tests where the operating temperature was controlled, either one or both of the TECs were used. Several operating temperature control tests were also performed using electrical heaters so that the power requirements could be compared.

In an LHP with multiple evaporators, only one $\mathrm{CC}$ will contain two-phase fluid and control the loop operating temperature under most circumstances. All other CCs will be filled with liquid [7]. The reason is that once a set of heat loads are applied to the evaporators, a corresponding pressure distribution is established for the entire loop. The CCs are most likely to be at different absolute pressures. The thermal environments surrounding these CCs are also different. The CCs that has the highest temperature is the one that will have two-phase fluid and control the loop operating temperature. As the heat loads among the evaporators and/or the condenser sink temperatures change, the pressure distribution in the loop and the thermal environments for the $\mathrm{CCs}$ also change. Thus, control of the loop operating temperature can switch from one $\mathrm{CC}$ to another. Even if all CCs are controlled at the same temperature, the thermal environments for the CCs will not be identical. Therefore, the above statements still hold true [8].

\section{$\underline{\text { Power Cycle Test }}$}

The power cycle test was performed by imposing a sudden, large step change in the evaporator heat loads. The purpose of this test was to verify that the LHP could adapt to a rapid change in the heat loads among various evaporators, and that the TECs could maintain the loop operating temperature at the desired set point temperature during the transient. 
Figure 7 shows the loop temperatures when the Condenser a and Condenser $2(\mathrm{C} 1 / \mathrm{C} 2)$ sink temperatures were kept at $273 \mathrm{~K} / 273 \mathrm{~K}$ and the Evaporator 1 and Evaporator 2 (E1/E2) heat loads varied as follows: $0 \mathrm{w} / 100 \mathrm{~W}, 25 \mathrm{~W} / 75 \mathrm{~W}, 50 \mathrm{~W} / 50 \mathrm{~W}, 75 \mathrm{~W} / 25 \mathrm{~W}, 100 \mathrm{~W} / 0 \mathrm{~W}$. As the E1/E2 heat loads changed, the temperatures of compensation Chamber 1 and Compensation Chamber 2 $(\mathrm{CC} 1 / \mathrm{CC} 2)$ also changed although in this test $\mathrm{CC} 1$ always controlled the loop operating temperature. Figure 8 shows the loop temperature when the same test was repeated but the CC saturation temperature was controlled at $303 \mathrm{~K}$. This test was conducted twice: first only CC1 temperature was controlled at $303 \mathrm{~K}$, and then both $\mathrm{CC} 1$ and $\mathrm{CC} 2$ temperatures were controlled at $303 \mathrm{~K}$. Regardless of how the CCs were controlled, the loop operating temperature was maintained at $303 \mathrm{~K}$ at all times as illustrated in Figure 8.

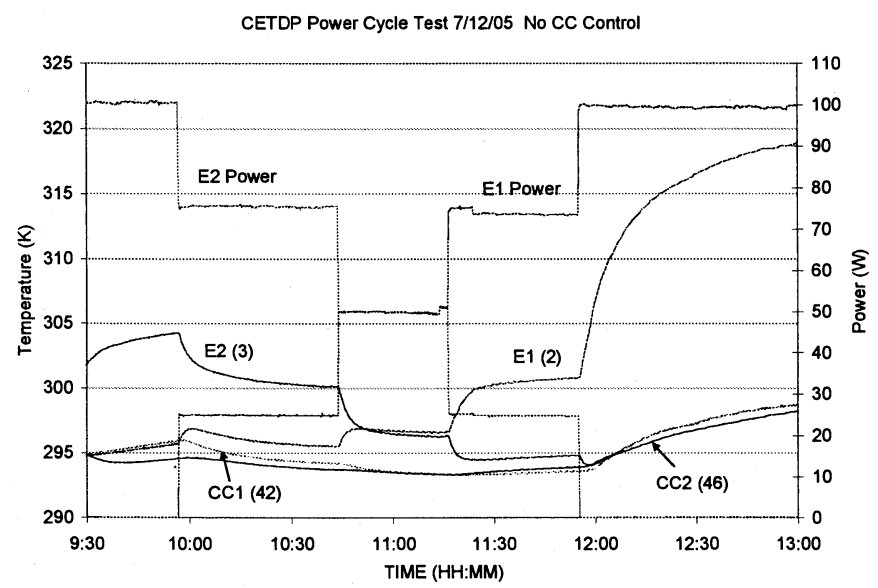

Figure 7. Power Cycle Test without Control of CC Temperatures

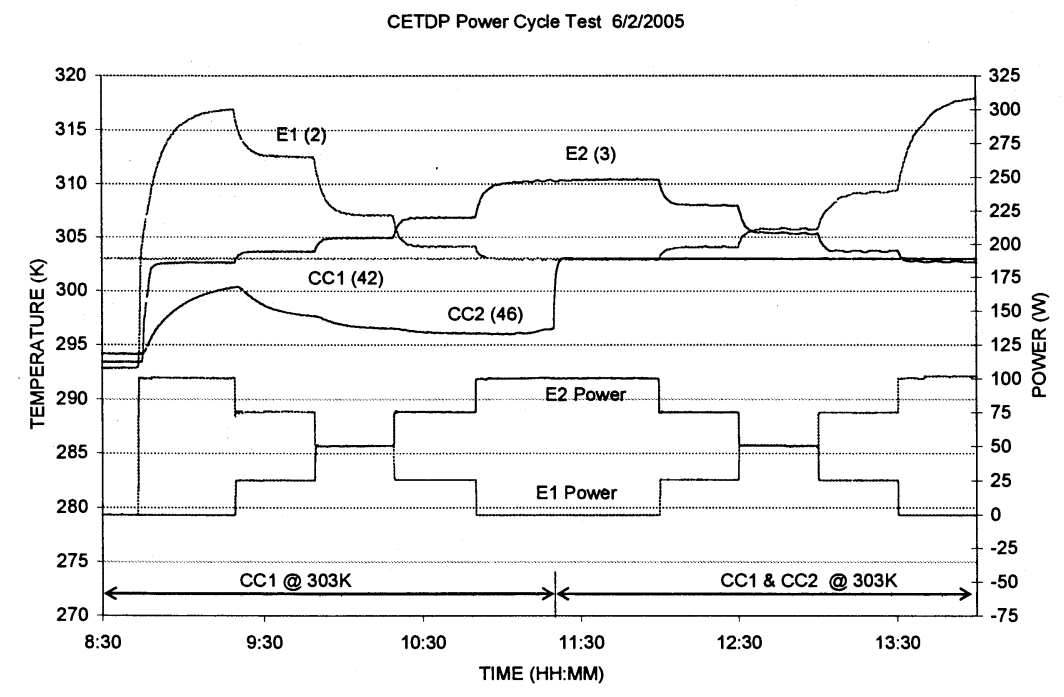

Figure 8. Power Cycle Test with Control of CC Set Point

\section{$\underline{\text { Sink Temperature Cycle Test }}$}

The sink temperature cycle test was conducted by imposing a sudden and large change in the condenser sink temperatures. The purpose of this test was to verify that the LHP could adapt to a 
rapid sink temperature change and the TECs could maintain the loop operating temperature at the desired set point temperature.

Figure 9 depicts the loop temperature when the $\mathrm{C} 1 / \mathrm{C} 2$ sink temperatures were cycled between $290 \mathrm{~K} / 295 \mathrm{~K}$ and $273 \mathrm{~K} / 265 \mathrm{~K}$ while $\mathrm{E} 1 / \mathrm{E} 2$ heat loads were kept constant at $50 \mathrm{~W} / 50 \mathrm{~W}$. In the first part of the test, neither CC was controlled. Consequently, temperatures of both CCs changed as the sink temperatures changed. In the second part of the test, the $\mathrm{CC} 1$ temperature was maintained at $303 \mathrm{~K}$ using the TEC. It is seen that the loop operating temperature was maintained at $303 \mathrm{~K}$ as the sink temperature varied. Between 15:07 and 15:17, a software problem occurred and the command to set the $\mathrm{CC} 1$ at $303 \mathrm{~K}$ could not be executed. The $\mathrm{CC} 1$ temperature decreased towards it natural operating temperature and the E1/E2 temperatures decreased accordingly. After the problem was fixed; the TEC raised the $\mathrm{CC} 1$ temperature back to $303 \mathrm{~K}$. In the last part of the test, both $\mathrm{CC} 1$ and $\mathrm{CC} 2$ were maintained at $303 \mathrm{~K}$ using TECs. The E1/E2 temperatures were unchanged regardless of whether one or both CCs were controlled.

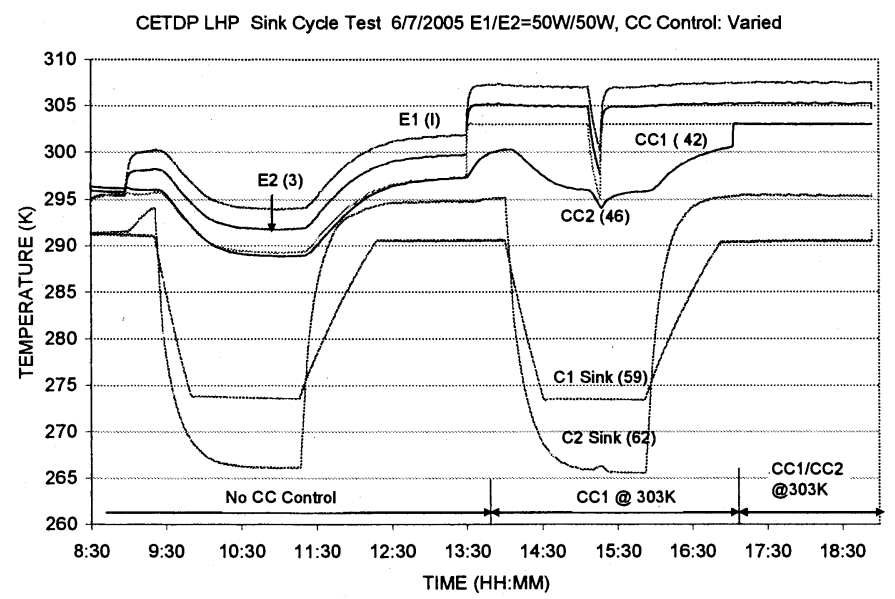

Figure 9. Sink Temperature Cycle Test

Figure 10 shows the loop temperature when E1/E2 heat loads varied between $75 \mathrm{~W} / 5 \mathrm{~W}$ and $5 \mathrm{~W} / 75 \mathrm{~W}$. Superimposed upon the heat load change was the change of the $\mathrm{C} 1 / \mathrm{C} 2$ sink temperature between $273 \mathrm{~K} / 263 \mathrm{~K}$ and $273 \mathrm{~K} / 293 \mathrm{~K}$. Either only one $\mathrm{CC}$ was controlled, or both CCs were controlled. It is seen that the loop was running at $303 \mathrm{~K}$ at all times. 


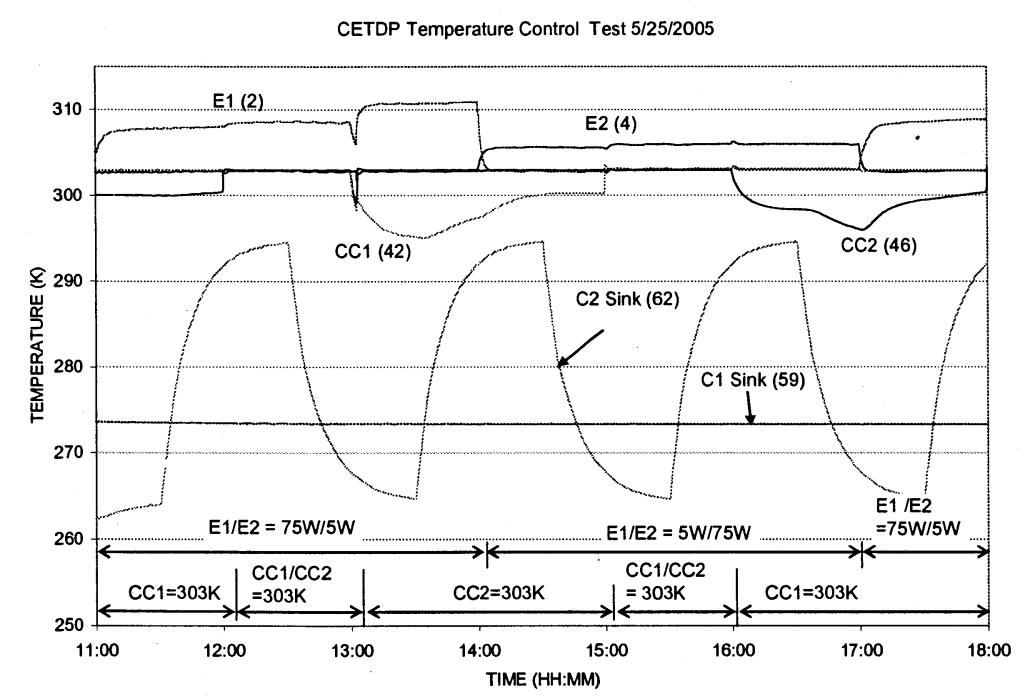

Figure 10. Power and Sink temperature Cycle Test

\section{$\underline{\text { High Power Test }}$}

When the LHP reaches its capillary limit, vapor will penetrate through the primary wick, leading to a sharp increase of the CC temperature. The thermal conductance of the evaporator will also decrease sharply, resulting in a sharp increase of the temperature difference between the evaporator and the $\mathrm{CC}$. Under most circumstances, the loop will reach a new steady state with the $\mathrm{CC}$ reaching a higher temperature. The $\mathrm{CC}$ temperature will return to its previous value as the as the heat load is reduced. However, a temperature excursion may result when the applied heat load far exceeds the loop's heat transport limit.

Figure 11 shows the loop temperatures during a high power test where a heat load was applied to E1 with $10 \mathrm{~W}$ increments. Neither CC temperature was controlled. CC2 was controlling the loop operating temperature for the E1/E1 heat load between $10 \mathrm{~W} / 0 \mathrm{~W}$ and $90 \mathrm{~W} / 0 \mathrm{~W}$. At 100W/0W, E1 reached its capillary limit. Vapor penetrated the E1 wick, and the $\mathrm{CC} 1$ temperature rose above the $\mathrm{CC} 2$ temperature. At $110 \mathrm{~W} / 0 \mathrm{~W}$, both $\mathrm{CC} 1$ and $\mathrm{E} 1$ temperatures rose at a much faster rate. As the heat load was reduced to $60 \mathrm{~W} / 0 \mathrm{~W}, \mathrm{E} 1$ recovered and the $\mathrm{CC} 1$ temperature dropped below the $\mathrm{CC} 2$ temperature. Figure 12 shows the same high power test except that the CC1 temperature was controlled at $303 \mathrm{~K}$ using the TEC. E1 reached its capillary limit at $100 \mathrm{~W} / 0 \mathrm{~W}$ as evidenced by the sharp rise of the E1 temperature. Nevertheless, the TEC was able to maintain the $\mathrm{CC} 1$ temperature at $303 \mathrm{~K}$ for the heat loads of $100 \mathrm{~W} / \mathrm{oW}$ and $110 \mathrm{~W} / 0 \mathrm{~W}$. 


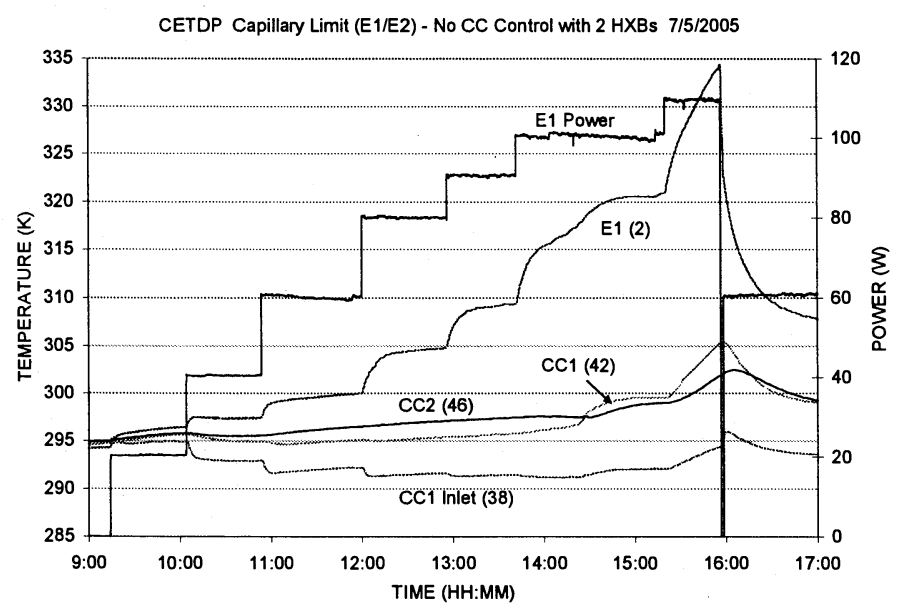

Figure 11. High Power Test without CC Temperature Control

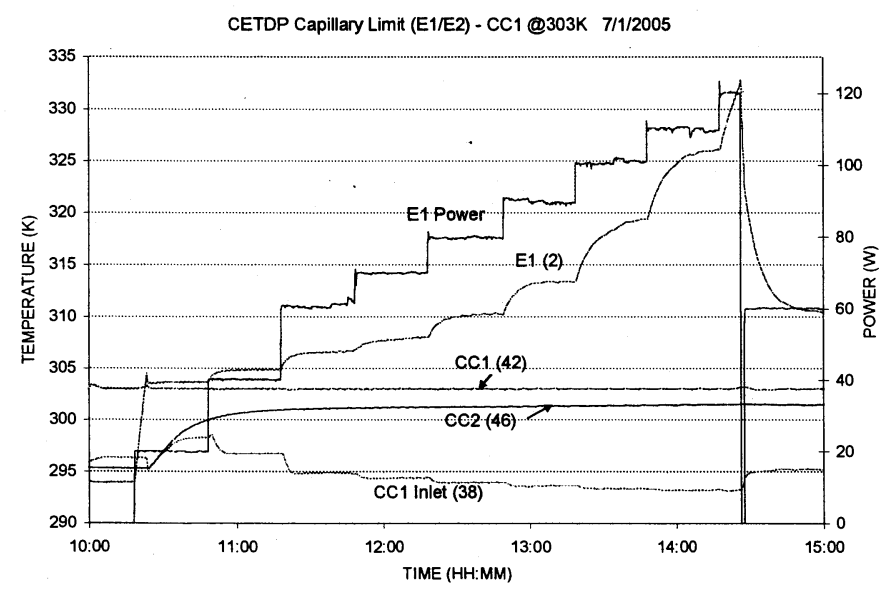

Figure 12. High Power Test with CC1 Temperature Controlled at 303K

\section{$\underline{\text { Low Power Test }}$}

The flow circulation in an LHP is very slow at low powers, and is near stagnation at extreme low powers. The low heat load represents another challenge on the LHP operation. In the low power range, the operating temperature tends to increase with a decreasing heat load in order for the returning liquid to provide enough subcooling to compensate for the heat leak from the evaporator to the CC. Using TECs, the loop operating temperature can be controlled below the ambient temperature, which cannot be accomplished using electrical haeters.

Figure 13 shows the loop temperature during the low power test. The ambient temperature was 294K. Initially, the CC temperatures were not controlled. E1/E2 heat loads increased from $2 \mathrm{~W} / 2 \mathrm{~W}$ to $5 \mathrm{~W} / 5 \mathrm{~W}$ to $10 \mathrm{~W} / 10 \mathrm{~W}$. The $\mathrm{CC}$ temperatures were higher than $294 \mathrm{~K}$ at these power levels. Then CC1/CC2 temperatures were controlled at $290 \mathrm{~K} / 290 \mathrm{~K}$ using TECs, and the E1/E2 heat loads decreased from $10 \mathrm{~W} / 10 \mathrm{~W}$ to $5 \mathrm{~W} / 5 \mathrm{~W}$ to $2 \mathrm{~W} / 2 \mathrm{~W}$. The TECs were able to maintain both CCs below the ambient temperature at these power levels. 


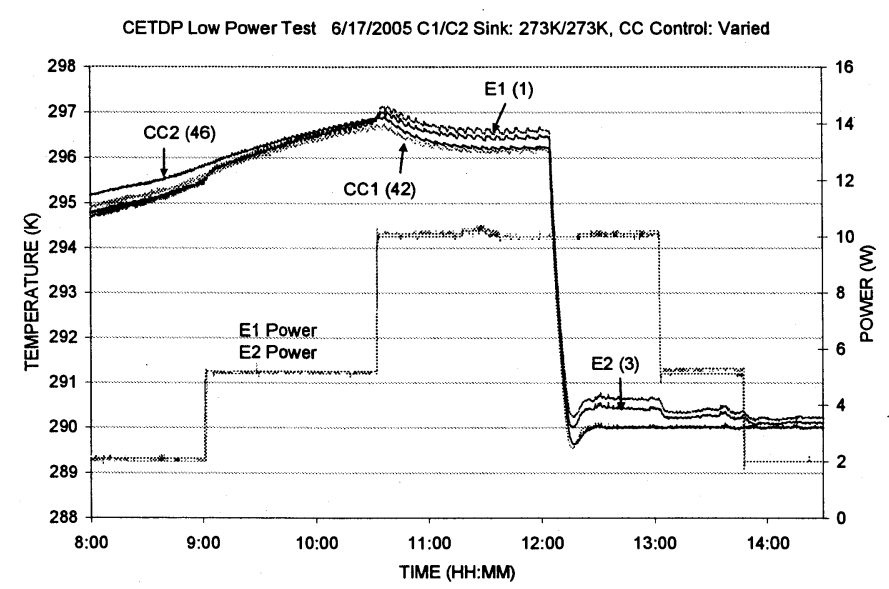

Figure 13. Low Power Test

\section{$\underline{\text { Set Point Temperature Change Test }}$}

One of the advantages of LHPs is that the loop operating temperature can be changed while the loop is in service. This offers great flexibility for spacecraft instrument temperature control. Figure 14 shows that the loop operating temperature was changed repeatedly by lowering the $\mathrm{CC} 1 / \mathrm{CC} 2$ temperatures from $308 \mathrm{~K} / 308 \mathrm{~K}$ to $278 \mathrm{~K} / 278 \mathrm{~K}$ with $5 \mathrm{~K} / 5 \mathrm{~K}$ increments. The $\mathrm{E} 1 / \mathrm{E} 2$ heat loads were kept constant at $20 \mathrm{~W} / 10 \mathrm{~W}$. Temperatures of the thermal masses and evaporators decreased in tandem with the $\mathrm{CC}$ temperatures, indicating that loop was running properly.

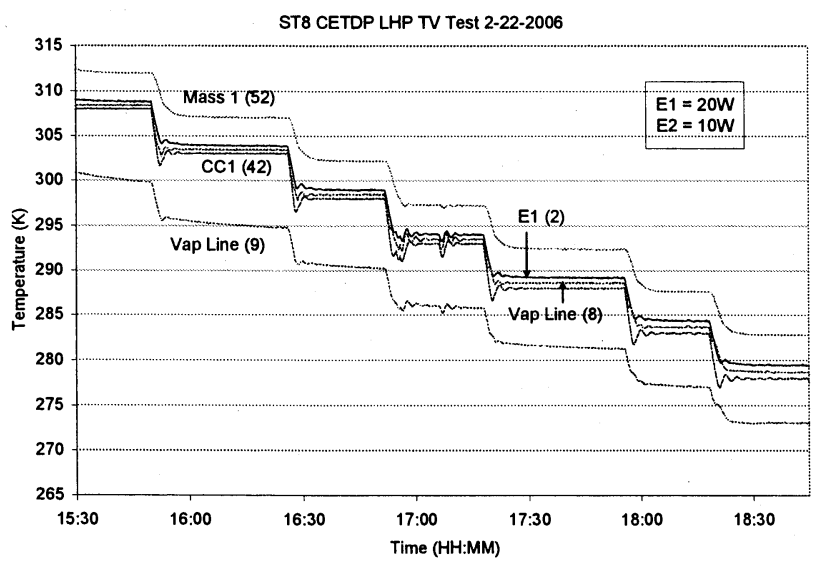

Figure 14. CC Set Point Temperature Change Test

\section{$\underline{\text { TEC Control Heater Power Test }}$}

As described earlier, using a TEC to control the CC temperature will consume less power than using electrical heaters. Tests were conducted to quantify the power savings by using both TECs and electrical heaters to control the $\mathrm{CC}$ temperature under otherwise the same condition. Two sets of tests were performed. In the first set, the $\mathrm{C} 1 / \mathrm{C} 2$ sink temperatures were maintained at $273 \mathrm{~K} / 273 \mathrm{~K}$ and the $\mathrm{CC} 1 / \mathrm{CC} 2$ temperatures were controlled at $303 \mathrm{~K} / 303 \mathrm{~K}$. The E1/E2 heat load increased from $10 \mathrm{~W} / 10 \mathrm{~W}$ to $70 \mathrm{~W} / 70 \mathrm{~W}$ with $10 \mathrm{~W} / 10 \mathrm{~W}$ increments. The $\mathrm{CC} 1 / \mathrm{CC} 2$ temperatures were first controlled by TECs. The test was repeated using electrical heaters to control the 
$\mathrm{CC} 1 / \mathrm{CC} 2$ temperatures. The power requirement at each E1/E2 heat load was recorded. The results are shown in Figure 15. The second set of test was similar to the first set except that the $\mathrm{C} 1 / \mathrm{C} 2$ sink temperatures were kept at $253 \mathrm{~K} / 253 \mathrm{~K}$ and the $\mathrm{CC} 1 / \mathrm{CC} 2$ temperatures were controlled at $313 \mathrm{~K} / 313 \mathrm{~K}$. Test results are shown in Figure 16 . The TECs realized $30 \%$ to $60 \%$ of power savings in these tests.

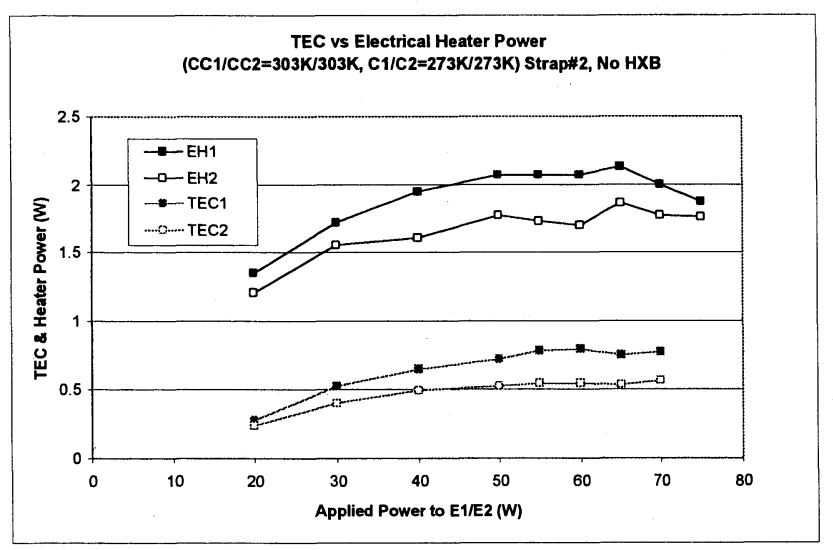

Figure 15. Comparison of TEC Power and Electrical Heater Power

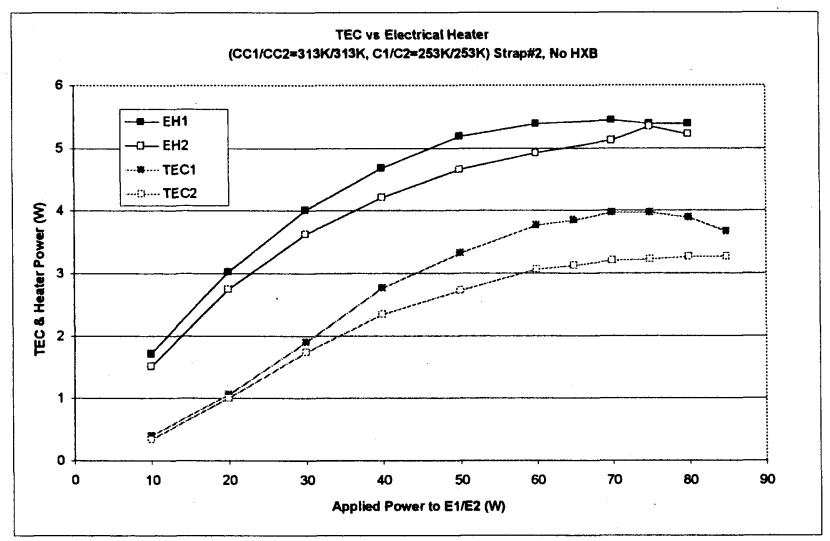

Figure 16. Comparison of TEC Power and Electrical Heater Power

\section{Conclusion}

TECs were used to control the operating temperature of a miniature LHP with two evaporators and two condensers. Test results showed excellent performance demonstrated by the TECs. The loop operating temperature was controlled within $\pm 1 \mathrm{~K}$ in all tests where the CC1/CC2 temperatures were controlled between $278 \mathrm{~K} / 278 \mathrm{~K}$ and $308 \mathrm{~K} / 308 \mathrm{~K}$, the E1/E2 heat loads varied between $2 \mathrm{~W} / 2 \mathrm{~W}$ and $100 \mathrm{~W} / 0 \mathrm{~W}$, and the $\mathrm{C} 1 / \mathrm{C} 2$ sink temperatures varied between $253 \mathrm{~K} / 253 \mathrm{~K}$ and $273 \mathrm{~K} / 293 \mathrm{~K}$. Either one or both of the CCs were controlled, and the loop showed the same operating temperature. The loop could adapt to rapid changes in evaporator heat loads and/or rapid changes in the sink temperatures. Using the TECs to cool the CCs, the loop could operate 
below the natural operating temperature and below the ambient temperature. Furthermore, the TECs realize 30 to 60 percent of power savings when compared to the traditional method of using electrical heaters.

\section{References}

1. Maidanik, Y., and Y. Fershtater, "Theoretical Basis and Classification of Loop Heat Pipes and Capillary Pumped Loops," $10^{\text {th }}$ International Heat Pipe Conference, Stuttgart, Germany, 1997.

2. Ku, J., "Operating Characteristics of Loop Heat Pipes," SAE Paper No. 1999-01-2007.

3. Baker, C., Butler, D., Ku, J., and E. Grob, "Acceptance Thermal Vacuum Tests of the GLAS Flight Loop Heat Pipe Systems," STAIF 2001, American Institute of Physics, Albuquerque, New Mexico, February 11-14, 2001.

4. Baker, C and Grob, E., "System Accommodation of Propylene Loop Heat Pipes for The Geoscience Laser Altimeter System (GLAS) Instrument," SAE paper No. 2001-01-2263, 2001.

5. Ottenstein, L., Ku, J., and D. Feenan, "Thermal Vacuum Testing of a Novel Loop Heat Pipe Design for the Swift BAT Instrument," Space Technology and Applications International Forum -2003, February 2-6, 2003, Albuquerque, New Mexico.

6. Choi, M., "Thermal Vacuum/Balance Test Results of Swift BAT with Loop Heat Pipe Thermal System", AIAA Paper No. 2004-5683, $2^{\text {nd }}$ IECEC, Providence, Rhode Island, August 16-19, 2004.

7. Ku, J. and G. Birur, "An Experimental Study of the Operating Temperature in a Loop Heat Pipe with Two Evaporators and Two Condensers SAE Paper No. 2001-01-2189, 2001.

8. Ku, J. and G. Birur, "Active Control of the Operating Temperature in a Loop Heat Pipe with Two Evaporators and Two Condensers”, SAE Paper No. 2001-01-2188, 2001. 